\title{
GAMBARAN PELAYANAN PRIMA RADIOLOGI DI INSTALASI RADIOLOGI RUMAH SAKIT PANTI RAPIH YOGYAKARTA
}

\author{
${ }^{1}$ Asih Puji Utami, ${ }^{2}$ Kesawa Sudarsih, ${ }^{3}$ Maulina Cahya Rochimayati \\ ${ }_{2}$ Fakultas Ilmu Kesehatan, Universitas 'Aisyiyah Yogyakarta \\ ${ }^{2,3}$ Prodi D III Teknik Rontgen STIKES Widya Husada Semarang
}

Email: asihpujiutami@unisayogya.ac.id

\begin{abstract}
Service in the field of radiology is one aspect that must be considered by the Yogyakarta Panti Rapih Hospital to improve service quality. Based on a preliminary study of the results of the questionnaire with a sample of 20 respondents who have done 2 of them, namely as many as three respondents disagree about the waiting time for all types of checks to get very fast results, a respondent does not agree on speed in providing services, this study aims to find out Overview of Prima Radiology Services at the Radiology Installation of Panti Rapih Hospital in Yogyakarta.

This type of research is quantitative descriptive with a cross sectional study approach. The study was conducted by taking a sample of 97 respondents by distributing questionnaires to some patients. After the data collected will then be analyzed using the SPSS program (Statistical Product and Service Solution) version 22.

Results: The results of the study based on the ability variable were $67 \%$ agreed. Based on attitude variables, as many as $82.5 \%$ agreed. Based on appearance variables, $57.7 \%$ agreed. Based on the attention variable as much as $84.5 \%$ stated strongly agree. Based on the action variable as much as $80.4 \%$ said they agreed, based on the variable responsibility, $83.5 \%$ agreed. Based on the 6 aspects of excellent service, it can be concluded based on good categories if the total score is baik 90 and not good if the total score is $\leq 90$, so that the score is $81.4 \%$ good, and $18.6 \%$ is not good. Radiology Installation of Panti Rapih Hospital in Yogyakarta should provide information on taking $X$-rays readings before and after the examination, it is necessary to increase patience with patients, be able to control emotions while providing services, have a sense of empathy for patients, provide fast service
\end{abstract}

Keywords : Excellent Service Radiology, Radiodiagnostic examination, Hospital

\section{Pendahuluan}

Di zaman globalisasi seperti sekarang ini, peningkatan kualitas pelayanan kesehatan di masyarakat mulai dari strategi perencanaan pelayanan dalam manajemen hingga pada implementasi dari rancangan terhadap kualitas pelayanan telah mengalami peningkatan (Muninjaya, 2004).

Salah satu jenis pelayanan penunjang medik dirumah sakit adalah pelayanan radiologi yang dilakukan oleh unit Instalasi Radiologi. Instalasi Radiologi merupakan tempat penyelenggaraan pelayanan radiologi dan radioterapi kepada pasien yang membutuhkan untuk menegakkan diagnosa yang cepat dan tepat. Instalasi
Radiologi dibagi menjadi tiga bagian yaitu, radiodiagnostik, radioterapi dan kedokteran nuklir (DEPKES RI, Permenkes RI No.780/Menkes/per/VIII /2008).

Dalam perkembangan dunia jasa dewasa ini dikenal istilah pelayanan prima (service excellence). Istilah pelayanan prima, yang artinya adalah kepedulian kepada pelanggan dengan memberikan layanan terbaik untuk memfasilitasi kemudahan pemenuhan kebutuhan dari mewujudkan kepuasannya, agar mereka selalu loyal kepada perusahaan (Barata, 2006). Pelayanan prima terdiri dari 6 unsur pokok yaitu, Kemampuan (Ability), Sikap (Attitude), Penampilan (Appearance), Perhatian 
(Attention), Tindakan (Action), dan Tanggung jawab (Accounttability).

Berdasarkan studi pendahuluan terhadap hasil kuisioner dengan 20 responden yang telah dilakukan oleh penulis di Instalasi Radiologi Rumah Sakit Panti Rapih Yogyakarta, responden berpendapat bahwa sebanyak tiga responden kurang setuju mengenai waktu tunggu untuk semua jenis pemeriksaan sampai dengan mendapat hasil sangat cepat, dua responden kurang setuju mengenai perhatian petugas radiologi terhadap keluhan pasien dan keluarganya, seorang responden kurang setuju mengenai ketrampilan pada saat melakukan pemeriksaan, seorang responden kurang setuju mengenai penampilan petugas yang rapi dan bersih, seorang responden kurang setuju mengenai petugas radiologi selalu tanggap dan mempunyai keinginan membantu masalah pasien, seorang responden kurang setuju mengenai kecepatan dalam memberikan pelayanan, seorang responden kurang setuju mengenai kelengkapan fasilitas di Instalasi Radiologi, seorang responden tidak setuju mengenai keramahan dan kesopanan petugas terhadap pasien yang datang, seorang responden tidak setuju mengenai kecepatan dalam memberikan pelayanan, dan seorang responden tidak setuju mengenai kelengkapan fasilitas di Instalasi Radiologi. Maka penulis tertarik untuk mengangkatnya ke dalam sebuah penelitian dengan judul "GAMBARAN PELAYANAN PRIMA RADIOLOGI DI INSTALASI RADIOLOGI RUMAH SAKIT PANTI RAPIH YOGYAKARTA".

\section{Metode}

Jenis penelitian yang digunakan dalam penelitian ini adalah kuantitatif deskriptif dengan pendekatan cross sectional study. Pengumpulan data, dilakukan dengan cara studi literatur, observasi dan kuesioner. Sampel dalam penelitian ini sebesar 97 pasien, pengambilan data dilakukan dengan cara menyebarkan kuesioner kepada pasien yang menjalani pemeriksaan radiodiagnostik. Setelah data terkumpul, langkah selanjutnya adalah melakukan pengolahan data dengan cara editing, koding, tabulasi dan akan dianalisis menggunakan program SPSS versi 22. Sehingga dari 6 aspek pelayanan primayang telah dianalisis dapat disimpulkan dalam 2 kategori yaitu baik jika skor total $\geq 90$ dan tidak baik jika skor total $\leq 90$ dan selanjutnya disajikan dalam bentuk tabel.

\section{Hasil Dan Pembahasan}
1. Penilaian Responden Karakteristik Responden
terhadap
a. Usia Responden

Tabel 1 Distribusi Frekuensi Berdasarkan Usia Responden di Instalasi Radiologi Rumah Sakit Panti

\begin{tabular}{|l|c|c|c|}
\hline No & Usia & Frekuensi & $\begin{array}{c}\text { Persentase } \\
(\%)\end{array}$ \\
\hline 1. & $\begin{array}{c}18-27 \\
\text { Tahun }\end{array}$ & 28 & 28,9 \\
\hline 2. & $\begin{array}{l}28-37 \\
\text { Tahun }\end{array}$ & 20 & 20,6 \\
\hline 3. & $\begin{array}{c}38-47 \\
\text { Tahun }\end{array}$ & 24 & 24,7 \\
\hline 4. & $\begin{array}{c}48-59 \\
\text { Tahun }\end{array}$ & 25 & 25,8 \\
\hline & Total & 97 & 100 \\
\hline
\end{tabular}

Berdasarkan tabel 1 tentang distribusi frekuensi usia responden dapat diketahui bahwa usia 18-27 tahun mempunyai frekuensi tertinggi sebanyak 28 dengan presentase $28,9 \%$, dan usia 28-37 tahun mempunyai frekuensi terendah sebanyak 20 dengan presentase 20,6\%.

Hasil penelitian Gambaran Pelayanan Prima Radiologi di Instalasi Radiologi Rumah Sakit Panti Rapih Yogyakarta ditinjau dari usia yaitu dengan kategori usia 18-27 tahun sebanyak 28 responden (28,9\%), usia 28-37 tahun sebanyak 20 responden $(20,6 \%)$, usia $38-47$ tahun sebanyak $24(24,7 \%)$, dan usia 48-59 tahun sebanyak 25 responden $(25,8 \%)$.

Menurut pendapat peneliti responden yang berusia muda lebih banyak memiliki tuntutan dan harapan terhadap pelayanan kesehatan. Responden yang berusia lebih tua pada umumnya lebih bijaksana, dan tidak memiliki tuntutan maupun harapan yang tinggi terhadap pelayanan yang diberikan.

Menurut Mardini dalam kuswara (2003), usia tua lebih puas terhadap pelayanan kesehatan yang diterima dibandingkan usia muda. Hal ini 
dikarenakan pasien lebih tua cenderung lebih menerima dibandingkan dengan pasien yang lebih muda, dokter dan perawat lebih respon dan perhatian terhadap pasien yang lebih tua.

\section{b. Jenis Kelamin Responden}

Tabel 2 Distribusi Frekuensi Berdasarkan Jenis Kelamin Responden di Instalasi Radiologi Rumah Sakit Panti Rapih Yogyakarta

\begin{tabular}{|l|c|c|c|}
\hline No & Jenis Kelamin & Frekuensi & $\begin{array}{c}\text { Persentase } \\
(\%)\end{array}$ \\
\hline 1. & Laki-laki & 40 & 41,2 \\
\hline 2. & Perempuan & 57 & 58,8 \\
\hline & Total & 97 & 100 \\
\hline
\end{tabular}

Berdasarkan tabel 2 tentang distribusi frekuensi jenis kelamin responden dapat diketahui bahwa perempuan mempunyai frekuensi sebanyak 57 dengan persentase 58,8\% dan laki-laki sebanyak 40 dengan persentase $41,2 \%$.

Hasil penelitian Gambaran Pelayanan Prima Radiologi di Instalasi Radiologi Rumah Sakit Panti Rapih Yogyakarta ditinjau dari jenis kelamin yaitu dengan kategori laki-laki sebanyak 40 responden $(41,2 \%)$, dan perempuan sebanyak 57 responden $(58,8 \%)$.

Menurut pendapat peneliti responden yang berjenis kelamin perempuan biasanya akan lebih selektif dalam menentukan jasa pelayanan daripada laki-laki yang bersifat tak acuh.

Jenis kelamin memiliki pengaruh pada pandangan terhadap jasa yang diberikan. Perempuan lebih banyak melihat penampilan secara detail, sementara laki-laki tidak mengindahkan hal tersebut (Gunarsa, 2008).

\section{c. Pendidikan Terakhir Responden}

Tabel 3 Distribusi rekuensi Berdasarkan Pendidikan Terakhir Responden di Instalasi Radiologi Rumah Sakit Panti Rapih Yogyakarta

\begin{tabular}{|l|c|c|c|}
\hline No & Pendidikan Terakhir & $\begin{array}{c}\text { Freku } \\
\text { ensi }\end{array}$ & $\begin{array}{c}\text { Persentase } \\
(\%)\end{array}$ \\
\hline
\end{tabular}

\begin{tabular}{|l|c|c|c|}
\hline 1. & SD & 5 & 5,2 \\
\hline 2. & SMP & 10 & 10,3 \\
\hline 3. & SMA & 40 & 41,2 \\
\hline 4 & Perguruan Tinggi & 42 & 43,3 \\
\hline & Total & 97 & 100 \\
\hline
\end{tabular}

Berdasarkan tabel 3 tentang distribusi frekuensi pendidikan terakhir responden dapat dilihat bahwa perguruan tinggi mempunyai frekuensi tertinggi sebanyak 42 dengan persentase 43,3\% dan SD mempunyai frekuensi terendah sebanyak 5 dengan persentase $5,2 \%$.

Hasil penelitian Gambaran Pelayanan Prima Radiologi di Instalasi Radiologi Rumah

Sakit Panti Rapih Yogyakarta ditinjau dari pendidikan terakhir yaitu dengan kategori SD sebanyak 5 responden $(5,2 \%)$, SMP sebanyak 10 responden (10,3\%), SMA sebanyak 40 responden (41,2\%), dan Perguruan Tinggi sebanyak 42 responden $(42,3 \%)$.

Menurut pendapat peneliti semakin tinggi pendidikan seseorang akan membuat seseorang semakin mengerti akan arti kesehatannya, sehingga menyebabkan semakin banyak tuntutan dan harapannya akan pelayanan kesehatan yang dibutuhkan. Sedangkan responden yang berpendidikan rendah pada umumnya hanya menerima pelayanan kesehatan yang diberikan tanpa menuntut dan berharap yang lebih.

Menurut Notoatmodjo (2005), bahwa tingkat pendidikan merupakan salah satu faktor yang mempengaruhi harapan dan persepsi pasien terhadap pelayanan kesehatan

\section{d. Pekerjaan}

Tabel 4 Distribusi Frekuensi Pekerjaan di Instalasi Radiologi Rumah Sakit Panti Rapih Yogyakarta

\begin{tabular}{|l|l|c|c|}
\hline No & \multicolumn{1}{|c|}{ Pekerjaan } & Frekuensi & $\begin{array}{c}\text { Persentase } \\
(\%)\end{array}$ \\
\hline 1. & $\begin{array}{l}\text { Ibu Rumah } \\
\text { Tangga }\end{array}$ & 29 & 29,9 \\
\hline
\end{tabular}




\begin{tabular}{|l|l|c|c|}
\hline 2. & $\begin{array}{l}\text { Pegawai Negeri } \\
\text { Sipil/TNI/POL } \\
\text { RI }\end{array}$ & 13 & 13,4 \\
\hline 3. & Pegawai Swasta & 15 & 15,5 \\
\hline 4 & Wiraswasta & 24 & 24,7 \\
\hline 5 & Mahasiswa & 10 & 10,3 \\
\hline 6 & Pelajar & 6 & 6,2 \\
\hline & $\begin{array}{c}\text { Total } \\
\text { Betdasarkan tabel }\end{array}$ & 97 tentang distribusi \\
\hline
\end{tabular}

frekuensi pekerjaan responden dapat dilihat bahwa ibu rumah tangga mempunyai frekuensi tertinggi sebanyak 29 dengan persentase 29,9\% dan pelajar mempunyai frekuensi terendah sebanyak 6 dengan persentase $6,2 \%$.

Hasil penelitian Gambaran Pelayanan Prima Radiologi di Instalasi Radiologi Rumah Sakit Panti Rapih Yogyakarta ditinjau dari pekerjaan yaitu dengan kategori Ibu rumah tangga sebanyak 29 responden $(29,9 \%)$, Pegawai Negeri Sipil/POLRI/TNI sebanyak 13 responden $(13,4 \%)$, pegawai swasta sebanyak 15 responden $(15,5 \%)$, wiraswasta sebanyak 24 responden $(24,7 \%)$,mahasiswa sebanyak $10(10,3 \%)$, dan pelajar sebanyak 6 responden $(6,2 \%)$.

Menurut pendapat peneliti responden yang bekerja pada umumnya memiliki banyak tuntutan dan harapan akan pelayanan kesehatan yang dibutuhkan. Responden yang tidak bekerja pada umumnya tidak memiliki tuntutan dan harapan yang tinggi terhadap pelayanan kesehatan, selama dapat sembuh lagi pasti akan kembali untuk berobat di tempat tersebut.

Menurut Barata (2006) menyatakan bahwa pekerjaan mempengaruhi tingkat kepuasan pasien terhadap pelayanan kesehatan yang diterimanya karena orang yang bekerja lebih menginginkan adanya keseimbangan antara pelayanan yang diterima dengan biaya yang dikeluarkan. 2. Penilaian Responden terhadap Aspek
Pelayanan Prima

a. Penilaian Responden terhadap
Kemampuan (Ability)
Tabel 5 Distribusi Jumlah Responden terhadap Penilaian Faktor Kemampuan (Ability) di Instalasi Radiologi Rumah Sakit Panti Rapih Yogyakarta

\begin{tabular}{|c|c|c|c|}
\hline No. & Penilaian & Jumlah & $\begin{array}{c}\text { Persentase } \\
(\%)\end{array}$ \\
\hline 1 & $\begin{array}{c}\text { Sangat Setuju } \\
\text { (SS) }\end{array}$ & 31 & 32 \\
\hline 2 & Setuju (S) & 65 & 67 \\
\hline 3 & $\begin{array}{c}\text { Kurang Setuju } \\
(\mathrm{KS})\end{array}$ & 1 & 1 \\
\hline 4 & $\begin{array}{c}\text { Tidak Setuju } \\
\text { (TS) }\end{array}$ & 0 & 0 \\
\hline & Total & 97 & 100 \\
\hline
\end{tabular}

Berdasarkan tabel 5 menunjukkan bahwa sebagian besar responden memberikan penilaian tentang faktor kemampuan (ability) di Instalasi Radiologi Rumah Sakit Panti Rapih Yogyakarta pada kategori sangat setuju dengan jumlah 31 responden (32\%), setuju dengan jumlah 65 responden (67\%), kurang setuju dengan jumlah 1 responden (1\%) dan tidak setuju dengan jumlah 0 responden $(0 \%)$.

Tetapi dari beberapa pernyataan dalam aspek kemampuan (ability)didapatkan satu pernyataan dengan kategori kurang setuju sejumlah 24 responden dengan persentase 24,7 \%yang berkaitan dengan petugas mampu memberikan hasil bacaan foto rontgen sesuai waktu yang telah dijanjikan.

Berdasarkan KMK N0 1014/Menkes/SK/XI/2008 bahwa untuk pengambilan hasil bacaan telah diterima oleh pelanggan / klien dalam waktu paling lambat 24 jam, maka hasil penelitian dari aspek pernyataan kemampuan (ability) masih sesuai dengan kententuan yang ada dalam aturan tersebut, sehingga menurut pendapat peniliti sebaiknya dalam memberikan informasi pengambilan hasil bacaan foto rontgenkepada pasien tidak hanya dilakukan setelah pasien tersebut dilakukan pemeriksaan tetapi sebelum 
dilakukan pemeriksaan juga perlu diberikan informasi mengenai pengambilan hasil bacaan foto rontgen secara jelas dan lengkap sehingga pasien memperoleh kejelasan untuk waktu pengambilan hasil bacaan.

Berdasarkan indikator pelayanan prima menurut Barata (2006), meliputi kemampuan pelayanan karyawan, berperilaku terpuji saat pelayanan, kedisiplinan penampilan karyawan, memahami keluhan serta keinginan, tanggap akan kebutuhan konsumen, kepedulian atas ketidakpuasan, dari hasil penelitian yang telah dilakukan dengan 97 responden yang melakukan pemeriksaan radiodiagnostik di Instalasi Radiologi Rumah Sakit Panti Rapih Yogyakarta sebagian aspek pelayanan prima sudah sesuai dengan indikator pelayanan prima yaitu kemampuan pelayanan karywan akan tetapi ada juga yang belum dan harus diperbaiki lagi atau ditingkatkan sehingga pelayanan prima yang diinginkan oleh semua pihak dapat terpenuhi.

\section{b. Penilaian Responden terhadap Sikap (Attitude)}

Tabel 6 Distribusi Jumlah Responden terhadap Penilaian Faktor Sikap (Attitude) di Instalasi Radiologi Rumah Sakit Panti Rapih Yogyakarta

\begin{tabular}{|c|l|c|c|}
\hline No & \multicolumn{1}{|c|}{ Penilaian } & Jumlah & $\begin{array}{c}\text { Persentase } \\
(\%)\end{array}$ \\
\hline 1 & $\begin{array}{l}\text { Sangat Setuju } \\
(\text { SS })\end{array}$ & 17 & 17,5 \\
\hline 2 & Setuju (S) & 80 & 82,5 \\
\hline 3 & $\begin{array}{l}\text { Kurang Setuju } \\
(\text { KS })\end{array}$ & 0 & 0 \\
\hline 4 & $\begin{array}{l}\text { Tidak Setuju } \\
(\text { TS })\end{array}$ & 0 & 0 \\
\hline \multicolumn{1}{|c|}{ Total } & 97 & 100 \\
\hline
\end{tabular}

Berdasarkan tabel 6 menunjukkan bahwa sebagian besar responden memberikan penilaian tentang faktor sikap (attitude) di Instalasi Radiologi Rumah Sakit Panti Rapih Yogyakarta pada kategori sangat setuju dengan jumlah 17 responden $(17,5 \%)$, setuju dengan jumlah 80responden $(82,5 \%)$, kurang setuju dengan jumlah Oresponden $(0 \%)$ dan tidak setuju dengan jumlah 0 responden $(0 \%)$.

Tetapi dari beberapa pernyataan dalam aspek sikap(attitude) didapatkan satu pernyataan dengan kategori kurang setuju sejumlah 12 responden dengan persentase $12,4 \%$ yang berkaitan denganpetugas memberikan edukasi terhadap pemeriksaan yang akan dilakukan dengan sabar sampai dimengerti oleh pasien, dan kategori tidak setuju memiliki aspek pernyataan yang sama dengan kategori kurang setuju hanya presentasenya saja lebih sedikit dibanding yang sebelumnya sebesar 1 responden dengan persentase $1 \%$.

Menurut pendapat peneliti untuk memberikan edukasi terhadap pemeriksaan yang akan dilakukan dengan sabar sampai dimengerti oleh pasien memang petugas harus mempunyai tingkat kesabaran yang lebih tinggi daripada pasien ataupun keluarganya tidak salah juga jika petugas harus menanyakan kembali baik kepada pasien atupun keluarganya apa sudah mengerti tentang edukasi yang telah dia berikan mengenai pemeriksaan yang akan dilakukan sehingga akan mengurangi resiko kesalah pahaman mengenai prosedur dalam pemeriksaan yang nantinya dilakukan.

Berdasarkan indikator pelayanan prima menurut Barata (2006), meliputi kemampuan pelayanan karyawan, berperilaku terpuji saat pelayanan, kedisiplinan penampilan karyawan, memahami keluhan serta keinginan, tanggap akan kebutuhan konsumen, kepedulian atas ketidakpuasan, dari hasil penelitian yang telah dilakukan dengan 97 responden yang melakukan pemeriksaan radiodiagnostik di Instalasi Radiologi Rumah Sakit Panti Rapih Yogyakarta sebagian aspek pelayanan prima 
sudah sesuai dengan indikator pelayanan prima yaitu berperilaku terpuji saat pelayanan akan tetapi ada juga yang belum dan harus diperbaiki lagi atau ditingkatkan sehingga pelayanan prima yang diinginkan oleh semua pihak dapat terpenuhi.

\section{c. Penilaian Responden tehadap Penampilan (Appearance)}

Tabel 7 Distribusi Jumlah Responden terhadap Penilaian Faktor Penampilan (Appearance) di Instalasi Radiologi

\begin{tabular}{|c|l|c|c|}
\multicolumn{1}{|c|}{ Rumah Sakit Panti Rapih Yogyakarta } \\
\hline No. & \multicolumn{1}{|c|}{ Penilaian } & Jumlah & $\begin{array}{c}\text { Persentase } \\
(\%)\end{array}$ \\
\hline 1 & $\begin{array}{l}\text { Sangat Setuju } \\
(\text { SS })\end{array}$ & 41 & 42,3 \\
\hline 2 & Setuju (S) & 56 & 57,7 \\
\hline 3 & $\begin{array}{l}\text { Kurang Setuju } \\
(\text { KS })\end{array}$ & 0 & 0 \\
\hline 4 & $\begin{array}{l}\text { Tidak Setuju } \\
(\text { TS })\end{array}$ & 0 & 0 \\
\hline & Total & 97 & 100 \\
\hline
\end{tabular}

Berdasarkan tabel 7 menunjukkan bahwa sebagian besar responden memberikan penilaian tentang faktor penampilan (appearance) di Instalasi Radiologi Rumah Sakit Panti Rapih Yogyakarta pada kategori sangat setuju dengan jumlah 41 responden (42,3\%), setuju dengan jumlah 56 responden $(57,7 \%)$, kurang setuju dengan jumlah 0 responden (0\%) dan tidak setuju dengan jumlah 0 responden $(0 \%)$.

Tetapi dari beberapa pernyataan dalam aspek penampilan (appearance) didapatkan satu pernyataan dengan kategori kurang setuju sejumlah 1responden dengan persentase $1 \%$ yang berkaitan dengantutur kata petugas tidak menyinggung perasaan saat melakukan pelayanan radiologi.

Menurut pendapat peneliti agar tutur kata tidak menyinggung perasaan saat melakukan pelayanan radiologi sebaiknya petugas harus dapat mengontrol emosi mereka pada saat sedang memberikan pelayanan kepada pasien dan tidak lupa selalu mengucapkan kata "Maaf" atau jika pasien itu sesama orang jawa menggunakan kata "Nuwun sewu" sebelum memberikan penjelasan sehingga resiko pasien ataupun keluargnya mungkin merasa tersinggung dengan ucapan petugas sangat kecil.

Berdasarkan indikator pelayanan prima menurut Barata (2006), meliputi kemampuan pelayanan karyawan, berperilaku terpuji saat pelayanan, kedisiplinan penampilan karyawan, memahami keluhan serta keinginan, tanggap akan kebutuhan konsumen, kepedulian atas ketidakpuasan, dari hasil penelitian yang telah dilakukan dengan 97 responden yang melakukan pemeriksaan radiodiagnostik di Instalasi Radiologi Rumah Sakit Panti Rapih Yogyakarta sebagian aspek pelayanan prima sudah sesuai dengan indikator pelayanan prima yaitu kedisiplinan penampilan karyawan akan tetapi ada juga yang belum dan harus diperbaiki lagi atau ditingkatkan sehingga pelayanan prima yang diinginkan oleh semua pihak dapat terpenuhi.

\section{d. Penilaian Responden terhadap Perhatian} (Attention)

Tabel 8 Distribusi Jumlah Responden terhadap Penilaian Faktor Perhatian (Attention) di Instalasi Radiologi Rumah Sakit Panti Rapih Yogyakarta

\begin{tabular}{|c|c|c|c|}
\hline No. & Penilaian & Jumlah & $\begin{array}{c}\text { Persentase( } \\
\%)\end{array}$ \\
\hline 1 & $\begin{array}{c}\text { Sangat Setuju } \\
\text { (SS) }\end{array}$ & 14 & 14,4 \\
\hline 2 & Setuju (S) & 82 & 84,5 \\
\hline 3 & $\begin{array}{c}\text { Kurang Setuju } \\
\text { (KS) }\end{array}$ & 1 & 1 \\
\hline 4 & $\begin{array}{c}\text { Tidak Setuju } \\
\text { (TS) }\end{array}$ & 0 & 0 \\
\hline
\end{tabular}




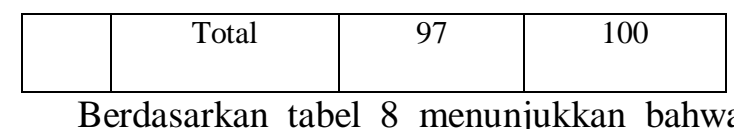

sebagian besar responden memberikan penilaian tentang faktor perhatian(attention) di Instalasi Radiologi Rumah Sakit Panti Rapih Yogyakarta pada kategori sangat setuju dengan jumlah 14 responden $(14,4 \%)$, setuju dengan jumlah 82 responden $(84,5 \%)$, kurang setuju dengan jumlah 1 responden (1\%) dan tidak setuju dengan jumlah 0 responden $(0 \%)$.

Tetapi dari beberapa pernyataan dalam aspek perhatian(attention) didapatkan satu pernyataan dengan kategori kurang setuju sejumlah 9 responden dengan persentase $9,3 \%$ yang berkaitanmemberikan perhatian khusus terhadap setiap pasien.

Menurut pendapat peneliti tentang pernyataan memberikan perhatian khusus terhadap setiap pasien memang diperlukan karena bagi mereka yang kondisi fisiknya sedang lemah maka perhatian petugas akan mereka memang sangat diperlukan sehingga petugas harus selalu peduli dan ikut empati melihat keadaan pasien tetapi tidak menutup kemungkinan pada saat kondisi ramai petugas tidak dapat melakukan hal tersebut ke setiap pasien.

Berdasarkan indikator pelayanan prima menurut Barata (2006), meliputi kemampuan pelayanan karyawan, berperilaku terpuji saat pelayanan, kedisiplinan penampilan karyawan, memahami keluhan serta keinginan, tanggap akan kebutuhan konsumen, kepedulian atas ketidakpuasan, dari hasil penelitian yang telah dilakukan dengan 97 responden yang melakukan pemeriksaan radiodiagnostik di Instalasi Radiologi Rumah Sakit Panti Rapih Yogyakarta sebagian aspek pelayanan prima sudah sesuai dengan indikator pelayanan prima yaitu memahami keluhan serta keinginan akan tetapi ada juga yang belum dan harus diperbaiki lagi atau ditingkatkan sehingga pelayanan prima yang diinginkan oleh semua pihak dapat terpenuhi.

\section{e. Penilaian Responden terhadap Tindakan (Action)}

Tabel 9 Distribusi Jumlah Responden terhadap Penilaian Faktor Tindakan (Action) di Instalasi Radiologi Rumah Sakit Panti Rapih Yogyakarta

\begin{tabular}{|c|l|c|c|}
\hline No. & Penilaian & Jumlah & $\begin{array}{c}\text { Persentase } \\
(\%)\end{array}$ \\
\hline 1 & $\begin{array}{l}\text { Sangat } \\
\text { Setuju (SS) }\end{array}$ & 19 & 19,6 \\
\hline 2 & Setuju (S) & 78 & 80,4 \\
\hline 3 & $\begin{array}{l}\text { Kurang } \\
\text { Setuju (KS) }\end{array}$ & 0 & 0 \\
\hline 4 & $\begin{array}{l}\text { Tidak Setuju } \\
\text { (TS) }\end{array}$ & 0 & 0 \\
\hline & \multicolumn{1}{|c|}{ Total } & 97 & 100 \\
\hline
\end{tabular}

Berdasarkan tabel 9 menunjukkan bahwa sebagian besar responden memberikan penilaian tentang faktor tindakan(action) di Instalasi Radiologi Rumah Sakit Panti Rapih Yogyakarta pada kategori sangat setuju dengan jumlah 19 responden $(19,6 \%)$, setuju dengan jumlah 78 responden (80,4\%), kurang setuju dengan jumlah 0 responden $(0 \%)$ dan tidak setuju dengan jumlah 0 responden $(0 \%)$.

Tetapi dari beberapa pernyataan dalam aspek tindakan (action) didapatkan satu pernyataan dengan kategori kurang setuju 5 responden dengan persentase $5,2 \%$ yang berkaitan petugas merespon keluhan yang ditampilkan pasien dan keluarganya dengan cepat.

Menurut pendapat peneliti tentang petugas merespon keluhan yang ditampilkan pasien dan keluarganya dengan cepat memang salah satu hal yang dingikan pelanggan terhadap penyedia jasa baik itu di rumah sakit maupun di penyedia pelayanan jasa umum lainya, pelanggan menuntut petugas agar melayani dengan cepat. Sedangakan di Instalasi Radiologi Rumah Sakit Panti Rapih Yogyakarta dirasa sudah melayani pasien dengan cepat dikarenakan pada saat kondisi ramai terkadang memang pasien harus sedikit bersabar untuk dapat dilayani oleh petugas.

Berdasarkan indikator pelayanan prima menurut Barata (2006), meliputi kemampuan pelayanan karyawan, berperilaku terpuji saat pelayanan, kedisiplinan penampilan karyawan, 
memahami keluhan serta keinginan, tanggap akan kebutuhan konsumen, kepedulian atas ketidakpuasan, dari hasil penelitian yang telah dilakukan dengan 97 responden yang melakukan pemeriksaan radiodiagnostik di Instalasi Radiologi Rumah Sakit Panti Rapih Yogyakarta sebagian aspek pelayanan prima sudah sesuai dengan indikator pelayanan prima yaitu tanggap akan kebutuhan konsumen akan tetapi ada juga yang belum dan harus diperbaiki lagi atau ditingkatkan sehingga pelayanan prima yang diinginkan oleh semua pihak dapat terpenuhi.

\section{f. Penilaian Responden terhadap Tanggung Jawab (Acccountability)}

Tabel 10 Distribusi Jumlah Responden terhadap Penilaian Faktor Tanggung jawab (Acccountability) di Instalasi Radiologi Rumah Sakit Panti Rapih Yogyakarta

\begin{tabular}{|c|l|c|c|}
\hline No. & \multicolumn{1}{|c|}{ Penilaian } & Jumlah & $\begin{array}{c}\text { Persentase( } \\
\%)\end{array}$ \\
\hline 1 & $\begin{array}{l}\text { Sangat Setuju } \\
(\mathrm{SS})\end{array}$ & 15 & 15,5 \\
\hline 2 & Setuju (S) & 81 & 83,5 \\
\hline 3 & $\begin{array}{l}\text { Kurang Setuju } \\
(\text { KS })\end{array}$ & 1 & 1 \\
\hline 4 & $\begin{array}{l}\text { Tidak Setuju } \\
\text { (TS) }\end{array}$ & 0 & 0 \\
\hline & \multicolumn{1}{|c|}{ Total } & 97 & 100 \\
\hline
\end{tabular}

Berdasarkan tabel 10 menunjukkan bahwa sebagian besar responden memberikan penilaian tentang faktor tanggung jawab(accountability) di Instalasi Radiologi Rumah Sakit Panti Rapih Yogyakarta pada kategori sangat setuju dengan jumlah 15 responden $(15,5 \%)$, setuju dengan jumlah 81 responden $(83,5 \%)$, kurang setuju dengan jumlah 1 responden (1\%) dan tidak setuju dengan jumlah 0 responden $(0 \%)$.

Tetapi dari beberapa pernyataan dalam aspek tanggung jawab(acccountability) didapatkan satu pernyataan dengan kategori kurang setuju sejumlah 18 responden dengan persentase 18,6 \% yang berkaitan dengan bertanggung jawab memberikan pelayanan yang prima dari mulai pasien mendaftar sampai mendapat hasil bacaan foto rontgen.dan kategori tidak setuju memiliki aspek pernyataan yang sama dengan kategori kurang setuju hanya presentasenya saja lebih sedikit dibanding yang sebelumnya sebesar 2 responden dengan persentase $2,1 \%$.

Menurut pendapat peneliti sebaiknya dalam memberikan pelayanan yang prima dari seiap pelayanan yang ada memang perlu ditingkatkan agar menjadi pelayanan yang lebih maksimal sesuai dengan harapan yang diinginkan oleh pasien atau pelanggan sehingga membuat mereka senang terhadap pelayanan yang telah kita berikan.

Berdasarkan indikator pelayanan prima menurut Barata (2006), meliputi kemampuan pelayanan karyawan, berperilaku terpuji saat pelayanan, kedisiplinan penampilan karyawan, memahami keluhan serta keinginan, tanggap akan kebutuhan konsumen, kepedulian atas ketidakpuasan, dari hasil penelitian yang telah dilakukan dengan 97 responden yang melakukan pemeriksaan radiodiagnostik di Instalasi Radiologi Rumah Sakit Panti Rapih Yogyakarta sebagian aspek pelayanan prima sudah sesuai dengan indikator pelayanan prima yaitukepedulian atas ketidakpuasan akan tetapi ada juga yang belum dan harus diperbaiki lagi atau ditingkatkan sehingga pelayanan prima yang diinginkan oleh semua pihak dapat terpenuhi

3. Penilaian Responden terhadap Pelayanan Prima Radiologi

Tabel 11 Distribusi Jumlah Responden terhadap Penilaian Pelayanan Prima Radiologi di Instalasi Radiologi Rumah Sakit Panti Rapih Yogyakarta

\begin{tabular}{|l|l|l|c|}
\hline No. & Penilaian & Jumlah & $\begin{array}{c}\text { Persentase( } \\
\%)\end{array}$ \\
\hline
\end{tabular}




\begin{tabular}{|c|c|c|c|}
\hline 1 & Baik & 79 & 81,4 \\
\hline 2 & Tidak Baik & 18 & 18,6 \\
\hline & Jumlah & 97 & 100 \\
\hline
\end{tabular}

Hasil penelitian mengenai Gambaran Pelayanan Prima Radiologi Di Instalasi Radiologi Rumah Sakit Panti Rapih Yogyakarta berdasarkan 6 variabel pelayanan prima yang meliputi (kemampuan, sikap, penampilan, perhatian, tindakan, dan tanggung jawab) dapat dikelompokkan kedalam 2 kategori yaitu, kategori baik jika total skor $\geq 90$ dan tidak baik jika total skor $\leq 90$ sehingga kedua kategori tersebut dapat digambarkan sebagai berikut, kategori baik $81,4 \%$ dan kategori tidak baik 18,6\%. Sehingga dapat dikatakan sebagian besar pelayanan prima radiologi di Rumah Sakit Panti Rapih Yogyakarta sudah sesuai dengan apa yang diharapkan oleh pelanggan atau pasien.

\section{Simpulan}

Pelayanan Prima Radiologi ditinjau dari 6 variabel pelayanan prima yang meliputi (kemampuan, sikap, penampilan, perhatian, tindakan, tanggung jawab) dapat dikelompokkan kedalam 2 kategori yaitu, kategori baik jika total skor $\geq 90$ dan tidak baik jika total skor $\leq 90$ sehingga kedua kategori tersebut dapat digambarkan sebagai berikut, kategori baik $81,4 \%$ dan kategori tidak baik $18,6 \%$.

\section{Saran}

1. Berdasarkan faktor kemampuan (ability), Instalasi Radiologi Rumah Sakit Panti Rapih Yogyakarta sebaiknya dalam memberikan informasi pengambilan hasil bacaan foto rontgen dilakukan sebelum dan sesudah dilakukan pemeriksaan dengan lengkap dan jelas sehingga pasien memperoleh kejelasan untuk waktu pengambilan hasil bacaan.

2. Berdasarkan faktor sikap (attitude), Instalasi Radiologi Rumah Sakit Panti Rapih Yogyakarta petugas sebaiknya perlu meningkatkan kesabaran kepada pasien dan keluarga pasien.

3. Berdasarkan faktor penampilan (appearance), Instalasi Radiologi Rumah Sakit Panti Rapih Yogyakarta petugas sebaiknya dapat mengontrol emosi mereka pada saat sedang memberikan pelayanan kepada pasien dan tidak lupa selalu mengucapkan kata "Maaf" atau jika pasien itu sesama orang jawa menggunakan kata "Nuwun sewu".

4. Berdasarkan faktor perhatian (attention), Instalasi Radiologi Rumah Sakit Panti Rapih Yogyakartasebaiknyamemiliki rasa kepedulian yang tinggi dan ikut empati melihat keadaan pasien.

5. Berdasarkan faktor tindakan (action), Instalasi Radiologi Rumah Sakit Panti Rapih Yogyakarta petugas sebaiknya dapat memberikan pelayanan dengan cepat dan maksimal.

6. Berdasarkan faktor tanggung jawab (acccountability), Instalasi Radiologi Rumah Sakit Panti Rapih Yogyakarta sebaiknya dalam memberikan pelayanan memang perlu ditingkatkan agar menjadi pelayanan yang prima sesuai dengan harapan yang diinginkan oleh pasien.

7. Pelayanan Prima Radiologi di Instalasi Radiologi Rumah Sakit Panti Rapih Yogyakarta sebagian besar sudah sesuai dengan harapan pasien tetapi untuk dapat memberikan pelayanan prima yang maksimal sebaiknya pelayanan yang sudah baik bisa ditingaktkan lagi guna memperoleh kepercayaan penuh dari pelanggan atau dalam hal ini adalah pasien dan pelayanan yang masih kurang bisa diupayakan agar kedepanya menjadi pelayanan yang lebih baik.

\section{Daftar Pustaka}

Barata, Atep Adya., 2006. Dasar - Dasar Pelayanan Prima. Jakarta : PT Elex Media Komputindo 
Gunarsa, Singgih., 2008. Psikologi Perawatan. Jakarta : Gunung Mulia

Menteri Kesehatan Republik Indonesia, 2008, Peraturan Menteri Kesehatan Nomor : 780/MENKES/PER/VIII/2008 tentang Penyelenggaraan Pelayanan Radiologi. Jakarta : Departemen Kesehatan.

Menteri Kesehatan Republik Indonesia,2008, Keputusan Menteri Kesehatan Nomor 1014/MENKES/SK/XI/2008 standar tentang Pelayanan Radiologi Diagnostik di Sarana Pelayanan Kesehatan.Jakarta : Departemen Kesehatan

Muninjaya, Anak Agung., Gde., 2004. Manajemen Kesehatan. Jakarta: Penerbit Buku Kedoteran EGC:220-234

Notoatmodjo, Soekidjo., 2005. Metodologi Penelitian Kesehatan. Jakarta: Rineka Cipta. 